\title{
BEHAVIOR OF STEEL HOLLOW SECTIONS UNDER BLAST LOAD
}

\author{
Asmaa A. Fekry ${ }^{1}$, Amr A. Nassr ${ }^{2}$, Ahmed M. Ismail ${ }^{3}$, Eslam M. Soliman ${ }^{4}$ and Ali Gamal ${ }^{5}$ \\ 1,2,3,4,5 Civil Eng. Dept., Faculty of Eng., Assiut Univirsity, Assiut, Egypt, \\ corresponding author E-mail: amrnassr@aun.edu.eg
}

\section{ABSTRACT}

Steel hollow section (SHS) tubular members have been widely used in the construction, infrastructure, onshore, offshore, mining, protective and security industries. Thus, strengthening of steel hollow tubular members is required to safely carry the dynamic loads to increase the security demands when the accidents, intentional impact, or explosive events occurred. In this paper, a finite element analysis tool, LS-DYNA is utilized to study the behaviors of (SHS) beam under a uniform transverse blast load. The explosive loads were sufficient in magnitude to cause plastic deformation of the cross-section (local deformation) and plastic flexural deformation of the overall member (global deformation). Different parameters were studied to investigate the effects of beam depth $(H)$, beam width $(B)$, support condition and axial load on the failure mode. The obtained displacement-time history from each simulation was recorded and compared. A numerical method for deriving pressure-impulse $(P-I)$ diagrams for (SHS) beam, which subjected to transient loads are described in this paper, which can be applied in the preliminary design of protective structures to establish safe response limits based on the given blast-loading. The proposed model of $(P-I)$ diagrams exhibited a good accuracy in predicting the pressureimpulse diagram to design the (SHS) beam under the extreme loads.

Keywords: Blast load; Steel hollow sections; LS-DYNA; Pressure-impulse diagram.

\section{INTRODUCTION}

Due to the increasing threat of terrorist attacks over the world in recent years, much research has been conducted to protect the important structures also to reduce human casualties from blast loads [1]. To ensure the safety of these structures, it is important to design them for levels of strength and ductility that would be adequate to resist the expected loads. Steel hollow sections are particularly advantageous because it has good torsional characteristics. The responses of the structural members to blast loading can include unacceptably large permanent deformations and even total failure [2]. Therefore, it is should be emphasized that investigating/expecting the behavior of steel structures under blast load pays the attention of the researchers to understand it.

There have been many experimental studied to investigate the steel hollow beams that is subjected to transverse blast loading or impact loading (e.g. vehicular impact, ship impact), in addition, analytical studies of impulsively loaded steel hollow beams have been also conducted. For examples, experimental Investigations of impulsively loaded steel hollow beams are performed by Wegener and Martin [3] on simply supported beams, and more recent study by Jama et al. [4] on clamped beams has been established. Regarding to these studies, it was shown that significant local crosssection distortions occur in conjunction with global bending deflections. On the other hand, experimental work on steel hollow and steel concrete filled sections was conducted by Bambach et al. [5]. In addition, aluminum hollow section beams have been studied by Bambach [6]. An extensive experimental program on the blast impact of clamped hollow beams that has square sections was carried out by Jama [7] and the major results from this study were published by Jama et al. [8]. Moreover, to the experimental studies that have been reported in [5-8], a semi-empirical analysis provided bounded solutions for the observed transverse plastic deformation of hollow members based on the assumption that the local collapse of the beam section and the global bending of the beam develop 
sequentially. Furthermore, an analytical twophase model was developed by Karagiozova [2] to describe the deformation process of a hollow square section beam subjected to impulsive loading; the proposed model can describe the temporal variation of the local and global deformations when the strain rate effects are taken into account during both the phases of deformation, reasonable agreement is obtained in comparison with the experimental data published in the literature [7, 8]. Remennikov and Uy [9] also proposed simplified engineering-level models for the near-filed blast impulse to predict the response of structural members to a near-field blast impulse and they presented the experimental results of explosive tests conducted on hollow and concrete filled tubular columns, the comparison of the analytically predicted dynamic response parameters of the concrete-filled steel tubular members with the experimental data shows very good agreement with the predicted failure mechanism and level of damage of the structural element.

Numerical simulation has been widely adopted as an effective way to study the behavior of structural members under different loading conditions since the laboratory tests are often costly and timeconsuming. One of the methods for the numerical simulation is Explicit FiniteElement (FE) analysis, which is most typically used for the blast response of structural members. The famous software that is available for the blast simulation includes: ABAQUS [10], ANSYS [11], AUTODYN [12] and LS-DYNA [13]. The study of Karagiozova [14] used ABAQUS software to study the behavior of circular hollow section beam, which subjected to blast. In that study, a reasonable agreement is observed for the characteristic displacements and deformed section shape compared to the experimental study. Alam [15] employed ABAQUS to study the behavior and the failure of carbon fiber reinforced polymer (CFRP) that strengthen square hollow section (SHS) steel columns under transverse impact loading, in this study confirms that the externally bonded CFRP composites are effective in enhancing impact resistance capacity of existing SHS steel columns. Jama [16] used LS-DYNA to study the temporal development of the local and global responses for square hollow steel beams subjected to a uniform transverse blast load; it was observed that the local cross-section deformation of the SHS beams is complete before any significant global beam bending deformation begins. Ritchie [17] used the experimental results from blast testing of cold-formed steel rectangular hollow sections (RHS) to validate explicit LS-DYNA numerical models, the comparison between the finite element results and the experimental results of the specimens showed good agreement between them.

As a conclusion from the previous discussion, LS-DYNA is the best software that can be used to simulate the behavior of the steel structure under the blast load and this refers to the acceptable expected results compared to the experimental tests and the facility of defining the loads and materials.

To design the SHS beams under the blast loads, a diagram should be investigated call pressure-impulse diagram (P-I). This considers one of the simplest methods for describing the structure's response under the applied explosive load [18, 19]. Therefore, Investigating this diagram can help the designers and researchers to obtain a safely design of the examined element. This diagram will be described in the next section to knowing how it can be investigated.

This paper presents a numerical method to evaluate the damage caused by blast loading in a steel hollow section (SHS) beam. High-fidelity physics-based finite element tool, LS-DYNA, is utilized in the current study to numerically simulate the dynamic response of (SHS) beam subjected to blast loads. Parametric studies are carried out to investigate the effects of cross-section dimension, support condition and axial load on the behavior of (SHS) strengthened 
beams subjected to transverse blast loading. Pressure-impulse diagrams are derived from numerically. Finally, analytical formulae are developed, which can be used to predict the pressure-impulse diagrams of (SHS) beam.

\section{Pressure-impulse diagram}

A Pressure-Impulse diagram is an isodamage curve (i.e. each combination of pressure and impulse produces the same damage level in a structural element loaded with a particular blast loading history) that represents a specific structural damage level for each combination of pressure and impulse that falls on the curve. [Figure-1] shows the primary features that define a Pressure-Impulse diagram. As observed, each Pressure-Impulse diagram has two asymptotes: impulsive asymptote and pressure asymptote. The impulsive asymptote is associated with the loads with very short duration relative to the structure's natural frequency. It represents the minimum impulse required to reach a particular level of damage. In the impulsive region, the structure response is sensitive only to the associated impulse and not to the peak pressure. On the other hand, pressure asymptote is associated with the loading that its duration is longer than the natural frequency of the structure, thus, it subjects the structure to quasi-static loading. In the quasi-static region of a Pressure-Impulse diagram, the structure's response becomes insensitive to impulse, however very sensitive to peak pressure. Hence, the horizontal asymptote represents the minimum required level of peak pressure to reach that particular damage level. The transition regime connecting the impulsive asymptote to the quasi-static asymptote is termed as the dynamic regime. In this regime, the structural response depends on both pressure and impulse. The load duration is the same order of magnitude as the structural natural period.

As observed in [Figure-1], the pressure impulse curve itself divides the Pressure Impulse space into two regions: the region above and to the right of the curve where the damage level of the structure component is exceeded, and that below and to the left where the level is lower. The pressure impulse diagrams usually contain a group of pressure impulse curves with different degrees of damage. These curves divide the Pressure-Impulse space into several regions, each corresponding to a particular level of damage, and the curves represent the boundaries between different damage levels such as low-, medium-, and high-damage. Since the Second World War, P-I diagrams have been widely accepted to predict the structural damage induced by impact-driven loadings such as blast loads [20-27].

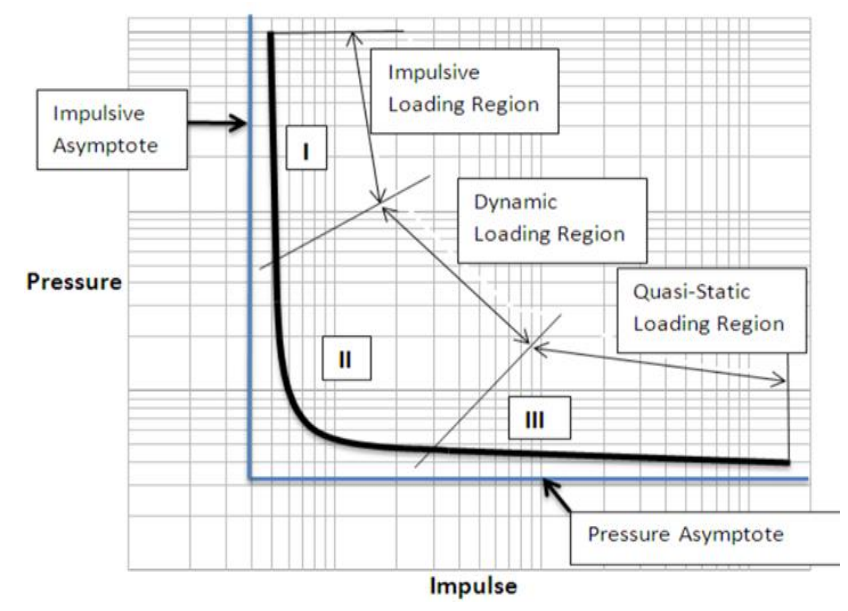

Fig. 1. Atypical pressure-impulse diagram. 


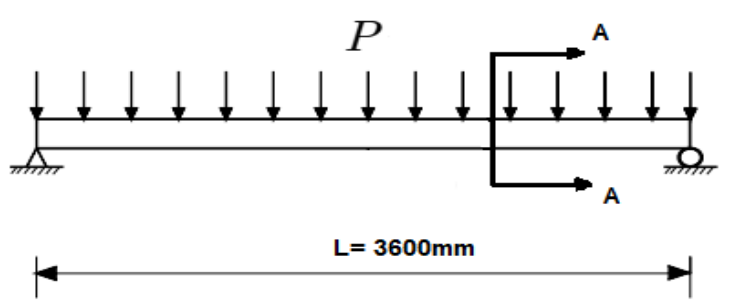

(a) Geometric configuration of the steel beam.

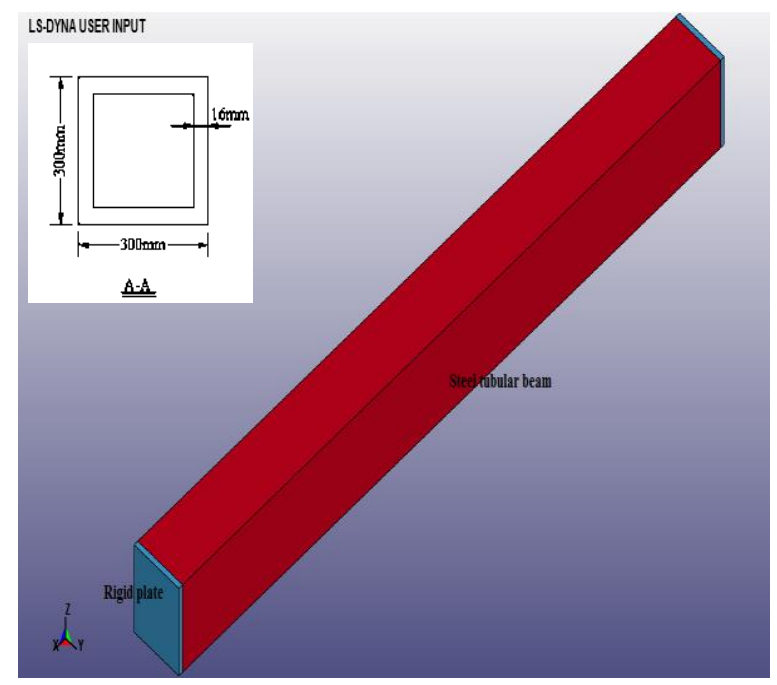

(b) Numerical model.

Fig. 1. Details of the steel tubular beam.

\section{EXPLICIT FINITE-ELEMENT MODELING}

LS-DYNA (version971) is a popular explicit FE analysis program that is used in the protective design industry. LS-DYNA incorporates several features, such as ConWep blast loading and strain-ratedependent material properties, that are beneficial for protective design. In this paper, the commercial software package LSDYNA was used to investigate the behaviors of steel hollow section beams under blast loading.

\subsection{Geometric and element properties}

A steel beam with a square section is numerically modeled, and the detailed configuration of the beam is illustrated in [Figure-2a] rigid plate at each end of the steel beam was included. The simulated beam in [Figure-2b], it was modeled with a finite element mesh consisting of 14,929 nodes and 7620 eight-node solid hexahedron fully integrated elements with nodal rotations (ELFORM = 3) using the ELEMENT_SOLID input card. The size of a solid element is $17 \times 17 \mathrm{~mm}$ at corner and $20.61 \times 17 \mathrm{~mm}$ at flat for beam cross section and $30 \mathrm{~mm}$ for beam span. Selection of this mesh size was after the convergence study to give careful results with reasonable run times.

\subsection{Strain rate effect}

When the steel tubular structures are subjected to blast loads, the steel may respond at very high strain rates in the order of $10 \sim 1000 \mathrm{~s}^{-1}$ or even higher. At these high strain rates, the apparent strength of these materials can increase significantly, by more than 50 percent. Therefore, the strain rate effect for steel needs is considered for a reliable simulation of structural response to blast loads. The effect of strain rate on the SHS is typically represented by a parameter, namely the dynamic increase factor (DIF). It is a ratio of the dynamic-to-static strength versus strain rate. Two constitutive equations for the strain-rate- sensitive behavior were used to plot the preceding DIF time histories. The first model was taken from Malvar [28] who proposed the following equation based on the results of dynamic tensile tests performed on steel rebar:

$$
\begin{aligned}
& D I F=\left(\frac{\dot{\varepsilon}}{10^{-4}}\right)^{\alpha} \\
& \quad \alpha \\
& =0.074 \\
& -0.040 \frac{f_{y}}{414}
\end{aligned}
$$

Where $\varepsilon$ is the strain rate in $s^{-1}$ and $f_{y}$ is the steel yield strength in MPa.

The model in Eq. (3) was based on the proposed model in the study of Cowper and Symonds [29]:

$D I F=1+\left(\frac{\dot{\varepsilon}}{C}\right)^{1 / q}$

Where $C$ and $q$ =constants for a particular material. These constants were taken for steel as $C=40$ and $q=5$. 


\subsection{Material models}

The steel material was modeled using the MAT03_PLASTIC_ KINEMATIC input card in LS-DYNA. In addition, the effect of the strain rate was taken into account by using the Cowpere-Symonds model to scale up the yield stress by the strain ratedependent factor as in Eq. (3). The parameters of this material model are shown in [Table-1].

Table 1. Material properties of steel tube.

\begin{tabular}{lllllllll}
\hline Para & Den & You & Poi & Yi & Tan & Fra & $C$ & $q$ \\
mete & sity & ng's & sso & eld & gent & ctur & & \\
r & (g/ & mod & n & str & mod & e & & \\
& $\mathrm{mm}^{3}$ & ulus & rati & ess & ulus & strai & & \\
& ) & (MP & o & (M & (MP & n & & \\
& & a) & & Pa & a) & & & \\
& & & & ) & & & & \\
\hline Valu & 0,00 & 200 &, 3 & 39 & 100 & $2 \%$ & 4 & 5 \\
$\mathrm{e}$ & 785 & 000 & & 2,5 & 0 & & 0 & \\
\hline
\end{tabular}

\subsection{Boundary condition and load}

Boundary constraints are applied on the surfaces of the rigid plate, the beam was modeled as pinned at one end and roller supported at the other end. All the nodes located on tow the horizontal centerlines of the external surface of one end plate were constrained, therefore all translations and rotations were prevented $(\delta x=\delta y=\delta z=0$, $\theta y=\theta z=0$ ) with the exception of rotation around the $x$-axis (hinge end). Similarly, all the nodes located on the other horizontal centerlines of the external surface of the other end plate $(\delta x=\delta y=0, \theta y=\theta z=0)$ were constrained. Thus, all translations and rotations were prevented, with the exception of translation in the $z$-direction and rotation around the $x$-axis (roller end), see [Figure3]. Blast loads applied on structures are usually identified by two parameters: peak pressure and positive impulse. The idealized triangular-shape pressure-time history was used to simulate the blast loading in the analysis, as shown in [Figure-4]. In addition, the blast load was uniformly distributed on the top of the beam. The blast pressure was defined using LS-DYNA input card DEFINE_CURVE.

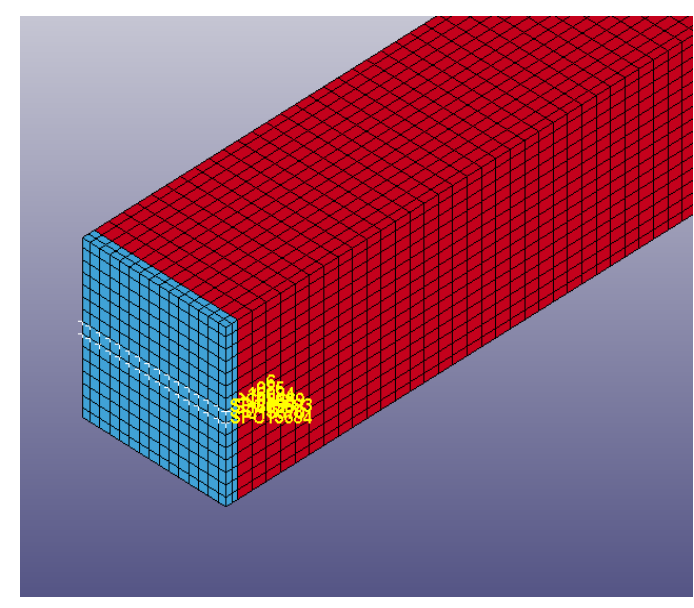

Fig. 2. Boundary conditions on external surface of the end plate.

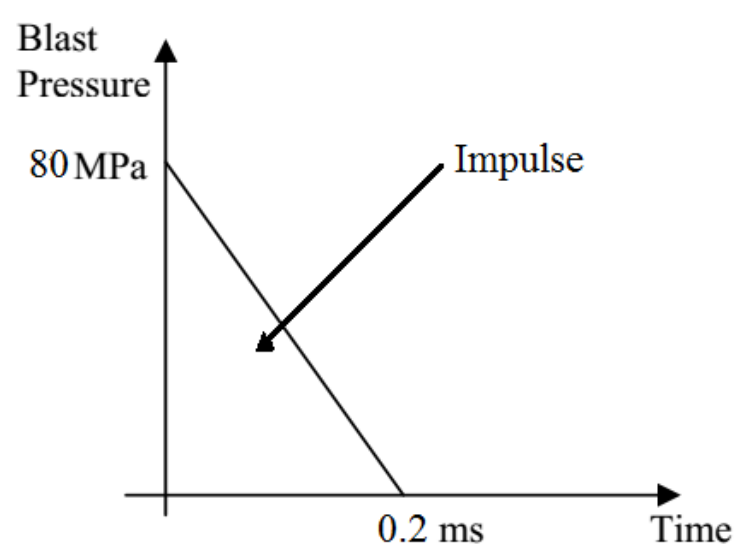

Fig. 3. Load time shape.

\section{VALIDATION OF THE NUMERICAL MODEL}

A numerical analysis of a full-scale wide-flange steel beam of W150× 24 section under blast loads was performed and its results were compared with the test results reported by Nassr [30]. A total of 24 steel specimens were tested, with a span length of $2413 \mathrm{~mm}$ (95 in.). In addition, the geometry of the specimens is shown in [Figure-5]. Each specimen was subjected to one of the four blast shots generated by different combinations of stand-off distance and charge weight and each shot involved the testing of six specimens, which included three beams and three columns. For convenience, the specimens were tested in the vertical position and simply supported. It is worth noting that, all the steel specimens 
were pinned at the top and roller supported at the bottom. Moreover, each member had a 24.5-mm-thick (1 in.) steel plate welded to its end. [Figures-6 (a, b)] showed the front and side views of the test setup. Only the one beam from the experiment is analyzed herein with about $50 \mathrm{~kg}$ of ammonium nitrate/fuel oil (ANFO) at a standoff distance of $10.30 \mathrm{~m}$ was used to generate the blast environment.

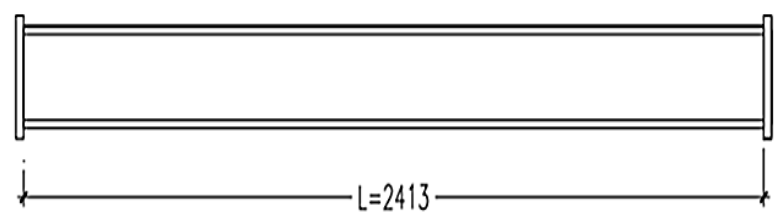

(a)

(b)

Fig. 4. (a) Typical test specimens and (b) crosssections of the test specimens.

The numerical simulations of the wideflange steel beam subjected to blast load are carried out in the nonlinear explicit solver, LS-DYNA. The LS-DYNA finite element model of specimen is shown in [Figure-7]. Material model PLASTIC_KINEMATIC (MAT_003) is used to model the steel beam. It is an elastic-plastic material behavior model with strain rate effect. In this material model, the required input material properties included the steel yield stress, density, fracture strain, and Poisson's ratio, which were considered as $470 \mathrm{MPa}, 7850 \mathrm{~kg} / \mathrm{m}^{3}$, 0.20 , and 0.30 , respectively. The blast pressure was defined using DEFINE_CURVE input card and subsequently applied to the surface of the flange facing the explosive charge using LOAD_SEGEMENT card. The maximum displacement for the examined beam (1B3) was recorded to be $6.9 \mathrm{~mm}$ in the explosive test and $5.9 \mathrm{~mm}$ by the LS-DYNA, as shown in [Figure-8].

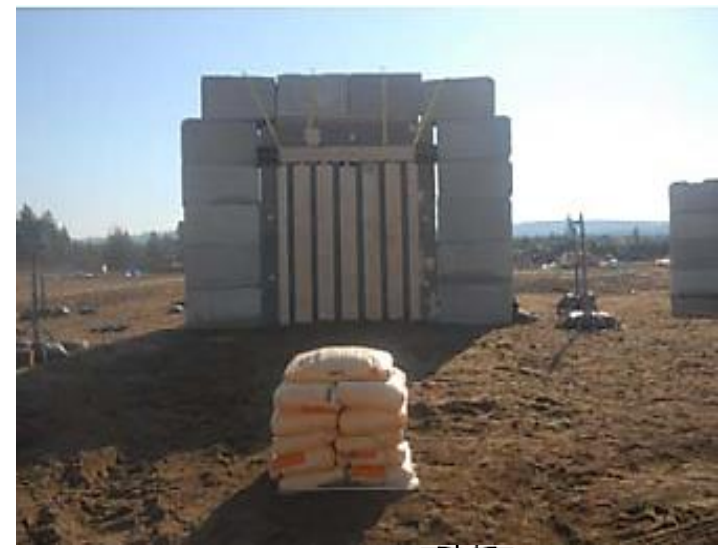

(a)Front view of the test setup.

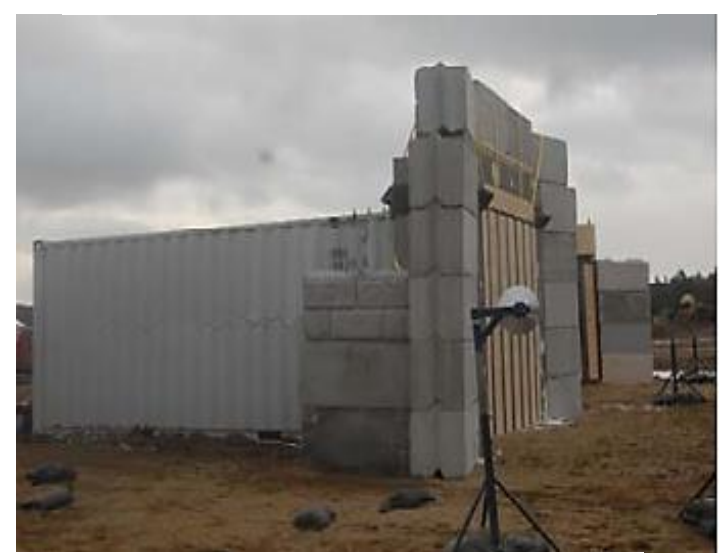

(b)Side view of the test setup

Fig. 6. Blast test setup.

\section{POSSIBLE DAMAGE MODES}

There are two damage modes have been observed during the numerical simulation of steel tube damage to an impulsive blast load (the blast load is usually of big peak and short duration). Firstly, there is a local deformation that transforms the cross section of the beam from its square shape to a shape in which the top half of the section undergoes a significant, deformation. The local deformations were complex and the measurement of the local deformation was taken to be the distance traversed by the top flange and is shown in [Figure-9a]. Secondly, there is a global deformation refer to the overall flexural deformation. The global deformations were measured as shown in [Figure-9b] and refer to the maximum permanent displacement of the bottom flange at the mid-length [8]. 


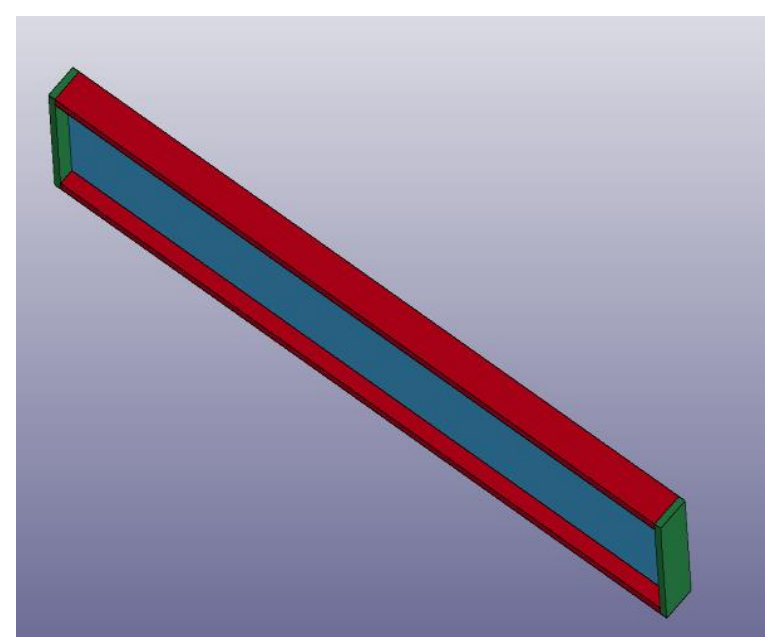

Fig. 5. Numerical model for validation in the present study.

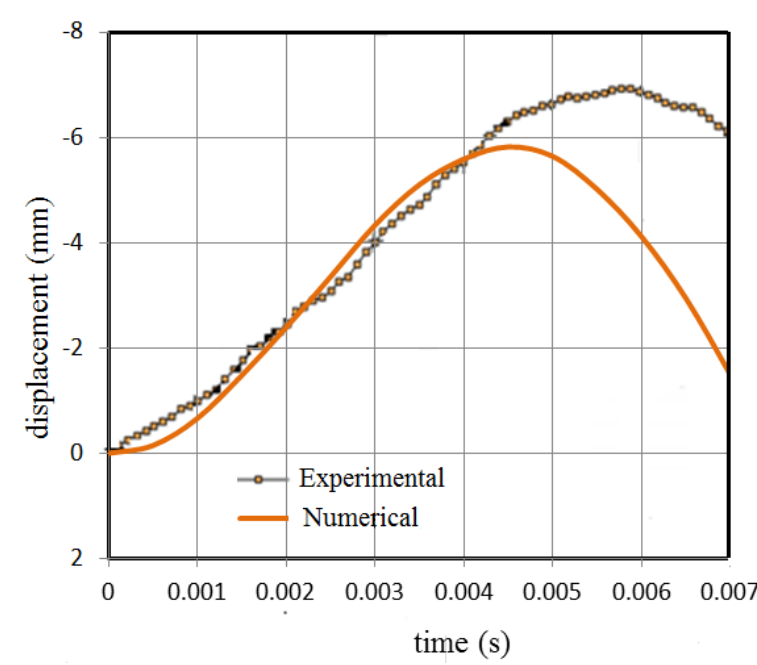

Fig. 6. Comparison between the numerical results and test results for beam1B3.

(a) Measurement of local
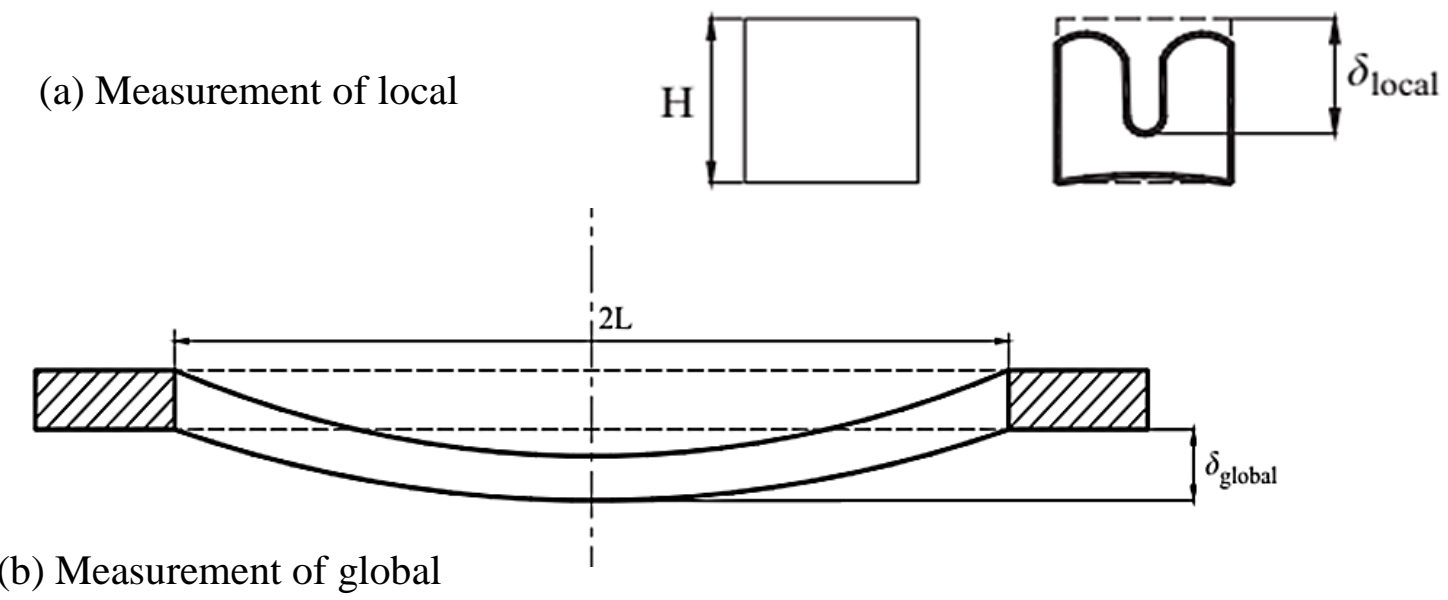

Fig. 7. Measurement of local cross-section and global. 


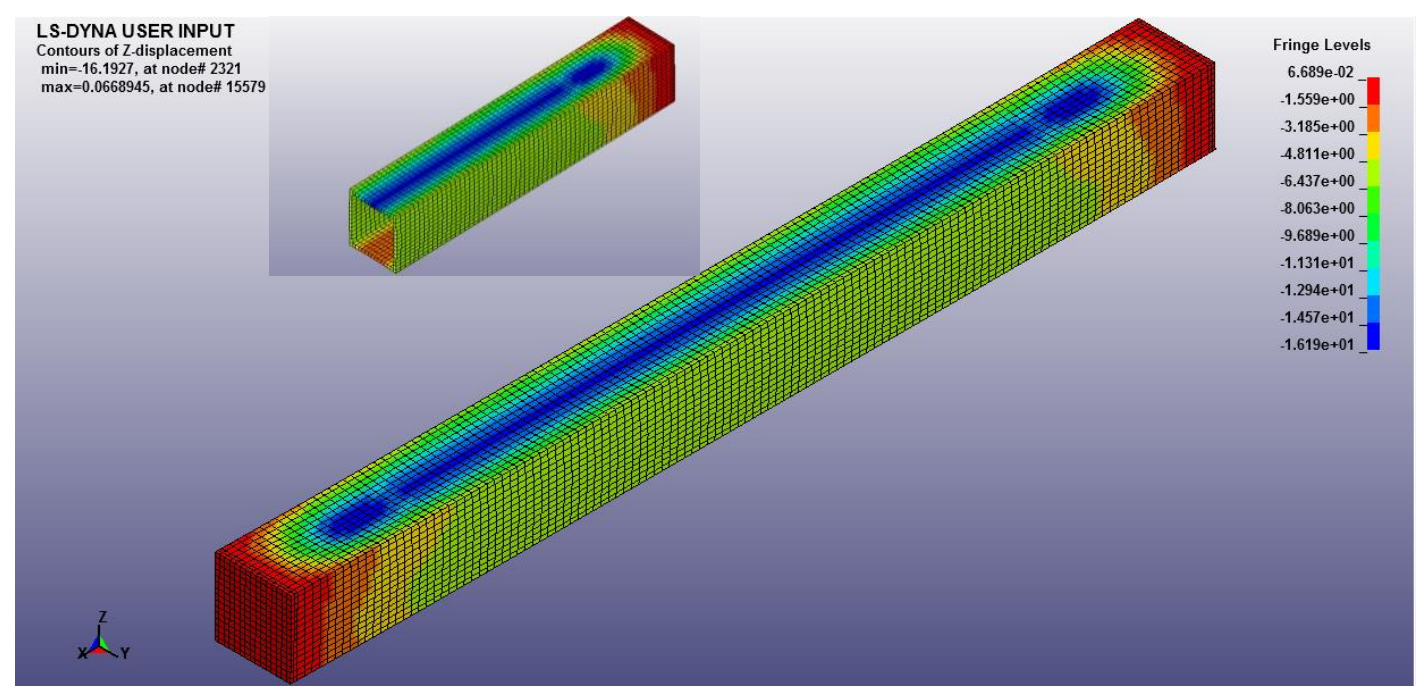

(a) Local deformation.

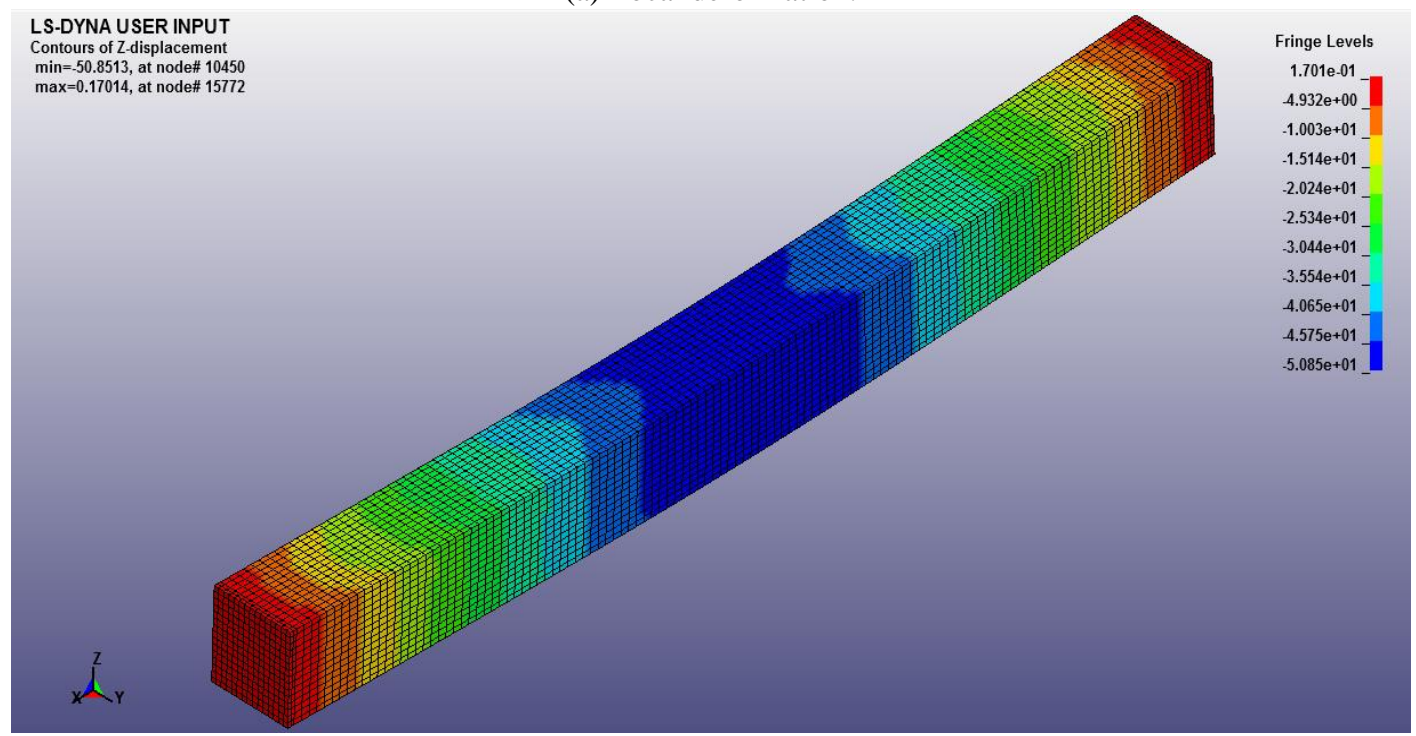

(b) Global deformation.

Fig. 8. Mechanical damage caused by blast load.

It was hypothesized by Wegener and Martin [3] that the local deformation is uniform along the beam, and that beam deformation occurs without local deformation resulting from beam bending. This suggests that the two mechanisms can be considered as sequential and uncoupled, and hence that a relatively simple approximate method of predicting both the local and global midspan displacements can be formulated. It was assumed that the local deformation took place first, and that the flexural deformation occurred after the cross-section deformation was complete.
The approximate analysis confirmed that the characteristic times for the two mechanisms of deformation were different by at least an order of magnitude. [Figure-10] presents the damage fringe of the steel tube subjected to a blast load identified as $\mathrm{P}=80 \mathrm{Mpa}, \mathrm{I}=8$ Mpa ms. The maximum permanent deflection for beam was found to be $5.8 \mathrm{~mm}$ at the midspan section of beam [Figure-11] shows the deflected shape of the beam, which appeared to be reasonably symmetrical about the centerline of the cross-section. 


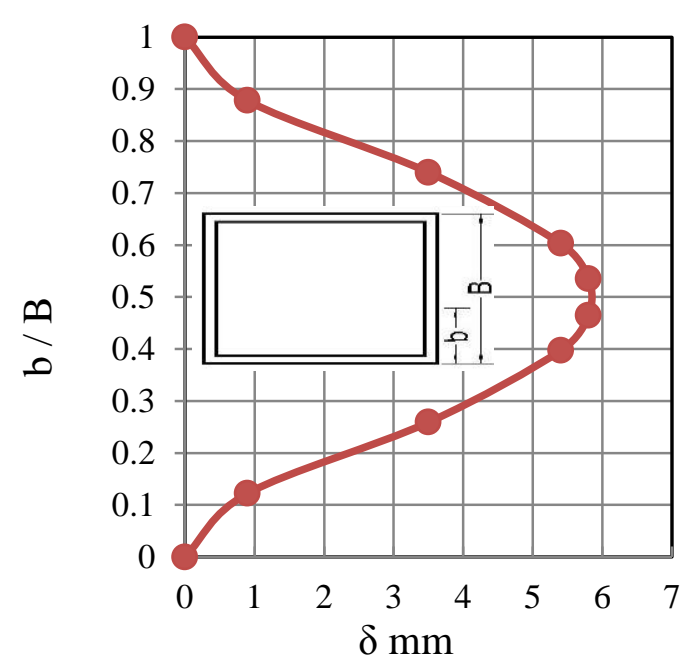

Fig. 9. Permanent deflected shape of the steel beam.

\section{PARAMETRIC STUDIES}

Systematic parametric studies are carried out by using the proposed numerical model to investigate the effect of different parameters on beam under blast load. The parameters investigated within the scope of this study are beam depth $\mathrm{H}$, beam width $\mathrm{B}$, support condition and axial load. [Table-2] lists the range of each parameter that is investigated in this paper. The gauge point is located on the center of each beam to measure the displacement-time history.

Table 2. Range of the parameters studied.

\begin{tabular}{cccc}
\hline Depth H (mm) & $\begin{array}{c}\text { Width } \\
\text { B (mm) }\end{array}$ & $\begin{array}{c}\text { Support } \\
\text { condition }\end{array}$ & Axial load \\
\hline $300 \mathrm{~mm}$ & $300 \mathrm{~mm}$ & Pin-Roller & $0 \%$ \\
$400 \mathrm{~mm}$ & $400 \mathrm{~mm}$ & $\begin{array}{c}\text { Fixed- } \\
\text { Fixed }\end{array}$ & $20 \%$ \\
& & & \\
\hline
\end{tabular}

\subsection{Beam depth, $H$}

Beam depth is an important factor to increase blast-load resistance of the beam. The results obtained showed that increase the beam depth tremendously increases the blast-load resistance as shown in [Figure12]. This refers to the increase in the beam cross section, increases the moment of inertia and shear area, which increase the flexural, and shear resistance of the beam.

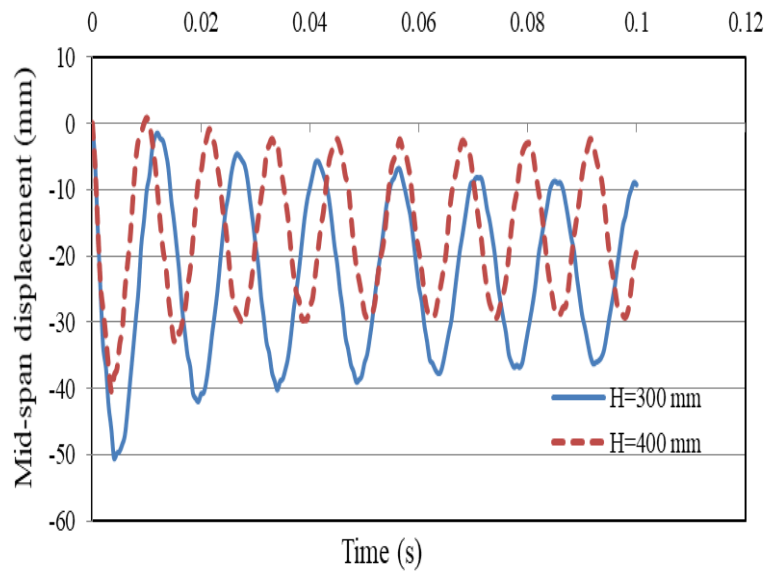

Fig. 10. The effect of varying the beam depth.

\subsection{Beam width, B}

The results of the analyses carried out for increase beam width shows that decrease the blast-load resistance of the beam, and this means that increasing beam width will increase the blast loads that acting on the beam. Although, it also increases the beam shear area and section moment of inertia, i.e., the beam shear and flexural resistance will also increase accordingly, the increase in flexural resistance capacity is less pronounced as compared to the increment of the blast load. This observation indicates that increase the beam width is not a good choice for strengthening the beam to resist blast load. [Figure-13] shows that varying the beam width on the maximum deflection.

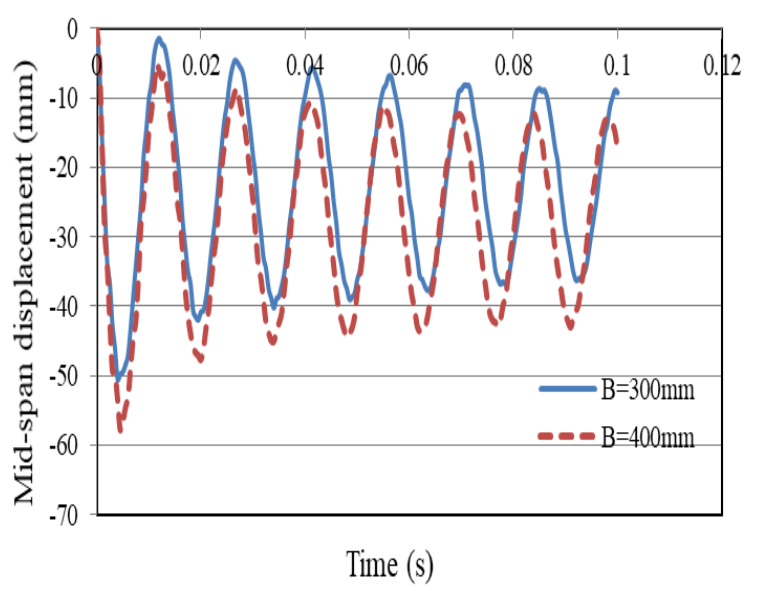

Fig. 11. The effect of varying the beam width.

\subsection{Support condition}

The support condition plays an important role when analyzing structural response and determining structural damage. 
In this study, the influence of support condition is also investigated by changing the pin-roller support condition to the fixedfixed support condition. [Figure-14] shows the comparison of displacement -time histories between beams with fixed ends and pinned-roller ends. In general, under the same blast load, beam with pinned -roller ends result in the maximum displacement more significantly than those with fixed ends.

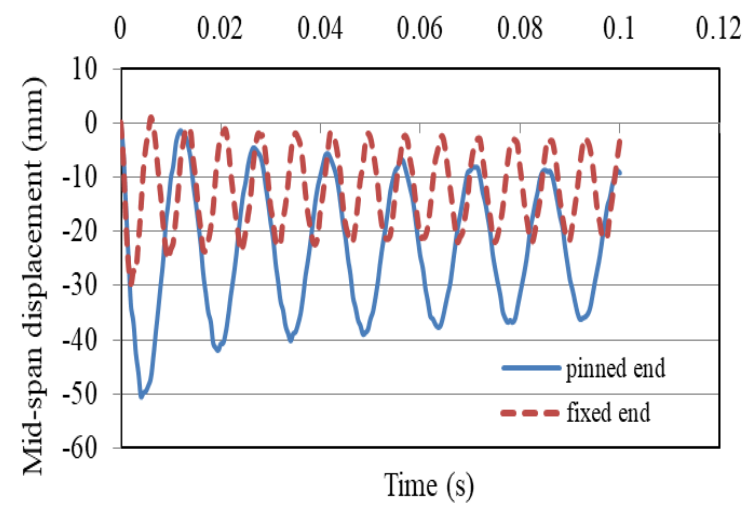

Fig. 12. The effect of applying pinned support and fixed support on the displacement.

\subsection{Axial load}

The axial load was defined as nodal forces at the roller supported end of the beam. It was applied as a ramp function over a period of $0.05 \mathrm{~s}$ and was maintained constant thereafter up to the end of the analysis. The blast loading was assumed to commence immediately after the axial load reached its steady state, as shown in [Figure15]. An axial force equal to $20 \%$ of the carrying capacity of the beam and the maximum deflection increases dramatically with increasing axial load as shown in [Figure-16]. The amplification of deflection is caused by two effects: one is the compressive membrane effect, which reduces the beam deflection and the other one is the "P- $\delta$ " effect when a beam deflects due to blast loads, the applied axial load causes a moment at the end that can further increase the deflection; as the deflection increases, the column reaches its plastic limit, transitioning from a gradual strength degradation to a rapid loss of strength due to buckling.

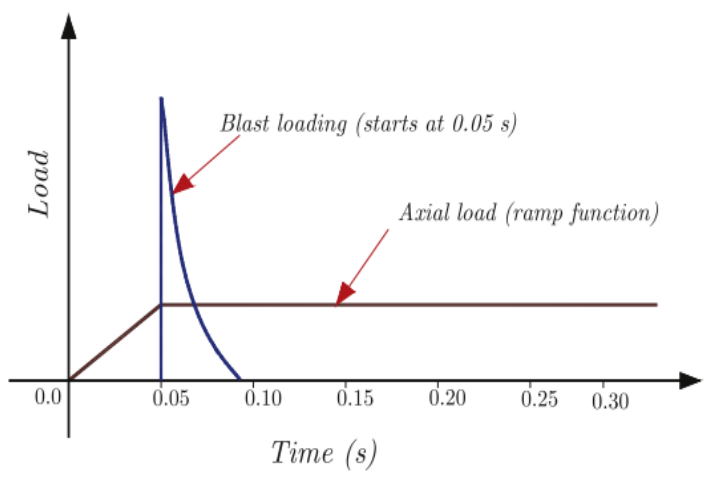

Fig. 13. Loading procedure for axial and blast

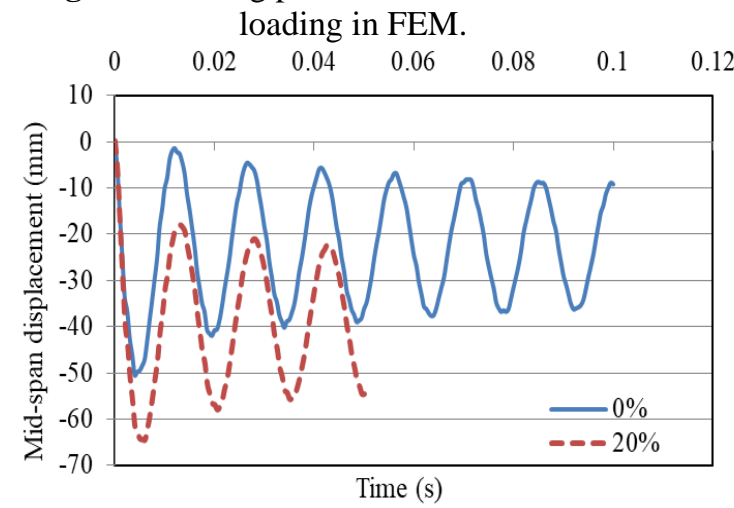

Fig. 14. Influence of axial load.

\section{NUMERICAL DERIVATION OF PRESSURE-IMPULSE DIAGRAM}

A pressure-impulse diagram can be numerically generated by having a set of data points that represents the same level of structural damage, however resulted from different pressure and impulse combinations. Although, the numerical method can accurately describe the dynamic behavior of a structure, it is very computationally expensive since it normally requires multiple trials to get one satisfactory point.

\subsection{Damage criterion}

Each pressure impulse curve represents a damage level that the structural element experiences due to the various blast loading conditions. For this study, the ratio of the commonly used mid-span displacement to the effective span of the beam is considered as the damage criterion. For each simulation, the maximum displacement of the central node at the mid-span cross-section of the beam is read from LS-DYNA's output. After running multiple simulations and following the procedure described above, 
the points whose damage levels are the same are connected to form a damage level curve, called the pressure impulse diagram for the specific level of structural damage. [Figure17] show the PI diagrams were generated to represent $1 \%, 3 \%$ and $5 \%$ damage per the criterion used in this research.

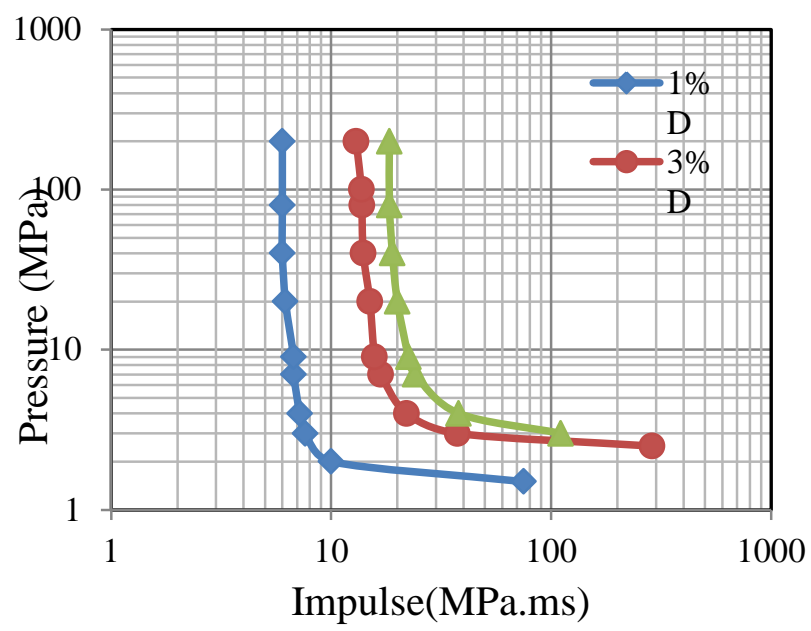

Fig. 15. Pressure-impulse curves for $1 \%, 3 \%$ and $5 \%$ damage level.

\subsection{Analytical formulae to generate pressure-impulse diagram}

Analytical formulae to predict the pressure-impulse diagram for steel tube beams are derived based on the numerical results using multivariate non-linear regression (curve fitting) method using MATLAB. The resulting equation is expressed as shown in Eq. (4).

$$
\begin{gathered}
\quad D \\
=a+b \times \log (I)+c \times \log (P)+d \\
\times(\log (I))^{2}+e \times \log (I) \log (P)+f \\
\times(\log (P))^{2}
\end{gathered}
$$

Where: $D$ represents the damage level; $a, b$, $c, d, e$ and $f$ are coefficients factors as displayed in [Table-3].

In the above equation, $D$ can be taken the values of 1,3 and 5 . The statistical results indicated that $R^{2}$ was 0 . 945. From the proposed model, a three-dimensional (3D) D-P-I diagram for SHS beam has been displayed in [Figure-18].
Table $r$. Coefficients developed for PI curves for the steel beam.

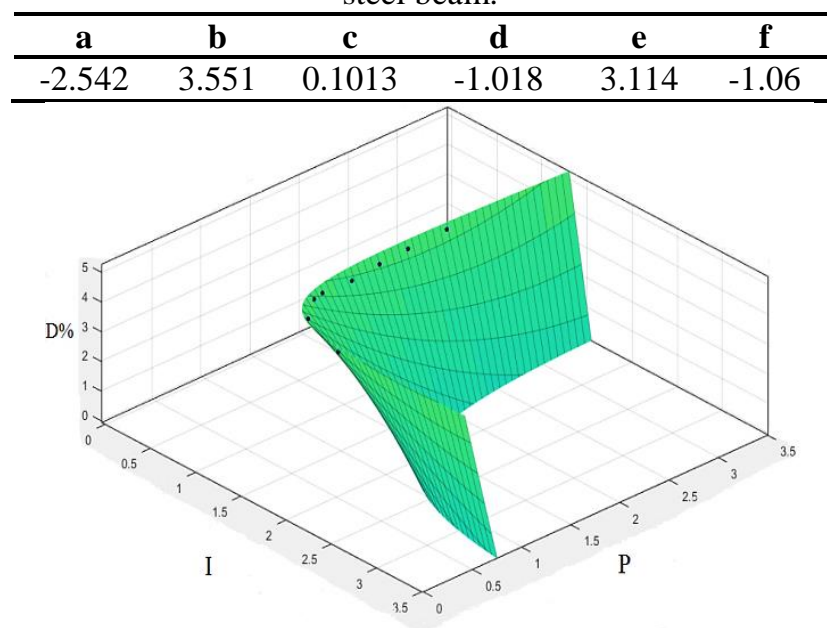

Fig. 16. (3D) D-P-I diagram for SHS beam.

\section{CONCLUSION}

In this paper, a numerical method to analyze the steel hollow section beam damage under blast loads using LS-DYNA software. In addition, a two-phase deformation model of the dynamic response of a hollow steel beam under an impulsive loading is developed to investigate the local and global deformation modes. Thus, the following conclusions can be drawn based on the presented numerical results in this paper:

1. The cross-section dimension is an important factor to blast-load resistance of the beam. With the increase of beam-depth increases the blast-load resistance. However, with the increase of beam-width, the blastload resistance of the beam decreases. This observation indicates that increasing the beam-width is not a good choice for strengthening the beam to resist the blast load.

2. Boundary conditions plays an important role in the behavior of the examined beam. Whereas, the beam with fixed-fixed boundary conditions is more stable under transverse blast loading.

3. Axial loading has an obvious effect on the failure mechanism of SHS columns. With the increase of axial loading lateral displacements of beams are increased, although the blast energy is constant. 
4. Based on the results of the derived pressure-impulse diagrams, an analytical equation for the pressure-impulse diagram for SHS beam is proposed. The proposed empirical formulae can be easily used to construct the pressure-impulse diagrams of SHS beam. The calculated pressure-impulse curves from the proposed analytical formulae are in a good agreement with those derived from numerical simulations.

Finally, the proposed model of pressureimpulse diagrams can help the designers and researchers to provide a safely design. In addition, smart/simply curves and a calculation sheet for design the SHS beans will be prepared in anther paper, which can help the designer/ researchers. Moreover, an extension of this work will be conducted to strengthening of this type of beams using FRP sheet.

\section{REFERENCES}

[1] Zhang, F., Wu, C., Zhao, X. L., Li, Z. X., Heidarpour, A., \& Wang, H. Numerical modeling of concrete-filled double-skin steel square tubular columns under blast loading. Journal of Performance of Constructed Facilities, 29(5), B4015002; 2015.

[2] Karagiozova, D., Yu, T. X., \& Lu, G. Transverse blast loading of hollow beams with square crosssections. Thin-Walled Structures, 62, 169-178; 2013.

[3] Wegener, R. B., \& Martin, J. B. Predictions of permanent deformation of impulsively loaded simply supported square tube steel beams. International journal of mechanical sciences, 27(1-2), 55-69; 1985.

[4] Jama H, Nurick G, Bambach M, Grzebieta R, Zhao X-L. Failure modes and thresholds of square tubular steel beams subjected to blast loads. In: Proceedings of the second international conference on design and analysis of protective structures, DAPS, Singapore, 13th-15th November 2006.

[5] Bambach, M. R., Jama, H., Zhao, X. L., \& Grzebieta, R. H. Hollow and concrete filled steel hollow sections under transverse impact loads. Engineering structures, 30(10), 2859-2870; 2008.

[6] Bambach, M. R. Behaviour and design of aluminium hollow sections subjected to transverse blast loads. Thin-Walled Structures, 46(12), 1370$1381 ; 2008$.
[7] Jama HH. The behaviour of tubular steel beams subjected to transverse blast loads [Ph.D. thesis]. Melbourne, Australia: Monash University; 2009.

[8] Jama, H. H., Nurick, G. N., Bambach, M. R., Grzebieta, R. H., \& Zhao, X. L. Steel square hollow sections subjected to transverse blast loads. ThinWalled Structures, 53, 109-122; 2012.

[9] Remennikov, A. M., \& Uy, B. Explosive testing and modelling of square tubular steel columns for near-field detonations. Journal of Constructional Steel Research, 101, 290-303; 2014.

[10] ABAQUS [Computer software]. Dassault Systèmes, Waltham, MA.

[11] ANSYS [Computer software]. ANSYS, Canonsburg, PA.

[12] AUTODYN. Interactive non-linear dynamic analysis software, version 4.2, user's manual. Century Dynamics Inc.; 2001.

[13] LS-DYNA [Computer software]. Livermore Software Technology Corporation, Livermore, CA.

[14] Karagiozova, D., Yu, T. X., Lu, G., \& Xiang, X. Response of a circular metallic hollow beam to an impulsive loading. Thin-Walled Structures, 80, 8090; 2014.

[15] Alam, M. I., \& Fawzia, S. Numerical studies on CFRP strengthened steel columns under transverse impact. Composite Structures, 120, 428-441; 2015.

[16] Jama, H. H., Bambach, M. R., Nurick, G. N., Grzebieta, R. H., \& Zhao, X. L. Numerical modelling of square tubular steel beams subjected to transverse blast loads. Thin-Walled Structures, 47(12), 1523 $1534 ; 2009$.

[17] Ritchie, C. B., Packer, J. A., Seica, M. V., \& Zhao, X. L. Behavior of steel rectangular hollow sections subject to blast loading. Journal of Structural Engineering, 143(12), 04017167; 2017.

[18] Merrifield, R. Simplified calculations of blast induced injuries and damage. Health and Safety Executive, Technology and Health Sciences Division; 1993.

[19] Smith P, Hetherington J. Blast and ballistic loading of structures. Great Britain, London: Butterworth-Heinemann Ltd; 1994. blast resistant connections. Comput Struct 1996;61(5):831-43.

[20] Shi YC, Hao H, Li ZX. Numerical derivation of pressure-impulse diagrams for prediction of $\mathrm{RC}$ column damage to blast loads. Int J Impact Eng, 35:1213-27; 2008. 
[21] Fallah, A. S., \& Louca, L. A. Pressure-impulse diagrams for elastic-plastic-hardening and softening single-degree-of-freedom models subjected to blast loading. International Journal of Impact Engineering, 34(4), 823-842; 2007.

[22] Li, Q. M., \& Meng, H. Pressure-impulse diagram for blast loads based on dimensional analysis and single-degree-of-freedom model. Journal of engineering mechanics, 128(1), 87-92; 2002.

[23] Li, Q. M., \& Meng, H. Pulse loading shape effects on pressure-impulse diagram of an elasticplastic, single-degree-of-freedom structural model. International journal of mechanical sciences, 44(9), 1985-1998; 2002.

[24] Ding, Y., Wang, M., Li, Z. X., \& Hao, H. Damage evaluation of the steel tubular column subjected to explosion and post-explosion fire condition. Engineering Structures, 55, 44-55; 2013.

[25] Shi, Y., Li, Z. X., \& Hao, H. A new method for progressive collapse analysis of RC frames under blast loading. Engineering Structures, 32(6), 1691$1703 ; 2010$.
[26] Mutalib, A. A., \& Hao, H. Development of PI diagrams for FRP strengthened RC columns. International journal of impact engineering, 38(5), 290-304; 2011.

[27] Nassr, A. A., Razaqpur, A. G., Tait, M. J., Campidelli, M., \& Foo, S. Strength and stability of steel beam columns under blast load. International Journal of Impact Engineering, 55, 34-48; 2013.

[28] Malvar, L. J. Review of static and dynamic properties of steel reinforcing bars. Materials Journal, 95(5), 609-616; 1998.

[29] Cowper, G. R., \& Symonds, P. S. Strainhardening and strain-rate effects in the impact loading of cantilever beams (No. TR-C11-28). Brown Univ Providence Ri; 1957.

[30] Nassr, A. A., Razaqpur, A. G., Tait, M. J., Campidelli, M., \& Foo, S. Experimental performance of steel beams under blast loading. Journal of Performance of Constructed Facilities, 26(5), 600619; 2011. 


\section{سلوك القطاعات المعدنية المجوفة تحت تأثير الحمل الانفجاري}

الملخص :

إن الأنابيب ذات القطاعات المعدنية المجوفة نستخدم على نطاق واسع في البناء والبنية التحتية والبرية والبحرية والتعدين والحماية والأمن الصناعي. وبالتالي، بلزم تقوية هذه القطاعات لتحمل الأحمال الديناميكية بأمان التي تتبع وقوع حوادث الانفجارات. لهذا في هذه الورقة البحثية، تم استخدام نظرية العناصر المنتهية (finite element analysis) باستخدام برنامج LS-DYNA المتفجرة كافية لتسبب تشوه لدن لكل من المقطع العرضي للكمرة وعلي كامل ابعاد الكمرة. تم عمل دراسة برامترية لبحث تأثنر العوامل المختلفة كعمق الكمرة وعرضها ونوع الركيزة والحمل المحوري علي وضع التشوه. وقد نم تسجيل ومقارنة الإزاحة التي تم الحصول عليها. وفى هذا البحث أيضا نم وصف طريقة عددية لاستتاج مخطط بياني بين الضغط والازاحة (P-I)للكمرات (SHS)، والتي تتعرض لأحمال مختلفة ، والتي يمكن تطبيقها في التصميم الاولى للمنشآت لوضع حدود استجابة آهنة لحمل الانفجار. وقد أظهر النموذج المقترح لمخطط (P-I) دقة جيدة في النتبؤ بمخط (P-I) لتصميم كمرة (SHS) تحت الأحمال القصوى. 